\title{
Article
}

\section{Coupled Oxidation-Extraction Desulfurization: A Novel Evaluation for Diesel Fuel}

Shurong Gao, Xiaochun Chen, Xiaotian Xi, Masroor Abro, Waheed Afzal, Rashid Abro, and Guangren Yu ACS Sustainable Chem. Eng., Just Accepted Manuscript • DOI: 10.1021/ acssuschemeng.8b04218 Publication Date (Web): 23 Jan 2019

Downloaded from http://pubs.acs.org on February 1, 2019

\section{Just Accepted}

"Just Accepted" manuscripts have been peer-reviewed and accepted for publication. They are posted online prior to technical editing, formatting for publication and author proofing. The American Chemical Society provides "Just Accepted" as a service to the research community to expedite the dissemination of scientific material as soon as possible after acceptance. "Just Accepted" manuscripts appear in full in PDF format accompanied by an HTML abstract. "Just Accepted" manuscripts have been fully peer reviewed, but should not be considered the official version of record. They are citable by the Digital Object Identifier (DOI®). "Just Accepted" is an optional service offered to authors. Therefore, the "Just Accepted" Web site may not include all articles that will be published in the journal. After a manuscript is technically edited and formatted, it will be removed from the "Just Accepted" Web site and published as an ASAP article. Note that technical editing may introduce minor changes to the manuscript text and/or graphics which could affect content, and all legal disclaimers and ethical guidelines that apply to the journal pertain. ACS cannot be held responsible for errors or consequences arising from the use of information contained in these "Just Accepted" manuscripts. 


\title{
Coupled Oxidation-Extraction Desulfurization: A Novel Evaluation for Diesel Fuel
}

\author{
Shurong $\mathrm{Gao}^{\mathrm{a}}$, Xiaochun Chen ${ }^{\mathrm{a}}$, Xiaotian Xi ${ }^{\mathrm{a}}$, Masroor $\mathrm{Abro}^{\mathrm{a}}$, Waheed Afzal ${ }^{\mathrm{b}}$, Rashid Abro ${ }^{\mathrm{c}}$, Guangren $\mathrm{Yu}^{\mathrm{a} *}$ \\ ${ }^{a}$ Beijing Key Laboratory of Membrane Science and Technology \& College of Chemical Engineering, Beijing University of Chemical \\ Technology, Beijing 100029, PR China \\ b School of Engineering, University of Aberdeen, UK \\ ${ }^{c}$ Department of Chemical Engineering, Dawood University of Engineering and Technology, Karachi, Pakistan \\ * Corresponding author, Tel./Fax: +86-10-6443-3570, E-mail: gryu@mail.buct.edu.cn
}

\begin{abstract}
:
In our previous experimental study, we have used a desulfurization method, i.e., coupled oxidation-extraction desulfurization. To develop a new insight into industrial-scale desulfurization process by this method, the process simulation study is of great importance. In this work, the industrial-scale of the coupled desulfurization processing of ULSD, wherein $\left[\mathrm{C}_{1}\right.$ pyr $] \mathrm{H}_{2} \mathrm{PO}_{4}$ is employed in the oxidative desulfurization process and DMF is employed in the extractive desulfurization process, has been examined through the Aspen Plus simulation. Sensitivity of various operating conditions, i.e., IL-to-oil ratio, DMF-to-oil ratio, operating temperature and pressure has been analyzed. Subsequently, the economical comparison of the proposed process and HDS is compared synthetically. It is observed that coupled desulfurization method can effectively remove the S-compounds from the diesel fuel to meet the requirement of stringent legislation of less than $10 \mathrm{ppm}$. The main objectives of this work are; (i) to propose and design an industrial-scale process of the coupled oxidation-extraction desulfurization of diesel, (ii) to obtain the optimal operating conditions, thus enabling the simulation and optimization of this desulfurization process, and (iii) to verify the experimental results and evaluate the feasibility to scale-up this technology. To the best of our knowledge, it is the first time to design an industrial-scale process for the coupled oxidation-extraction desulfurization of diesel fuel.
\end{abstract}

Keywords: Coupled oxidation-extraction, Desulfurization, Industrial-scale, Process simulation, Sensitivity analysis

\section{Introduction}

Desulfurization of diesel fuel is an essential process in oil refineries to meet the target of ultra-low-sulfur (ULSD)

or sulfur-free diesel fuel. ${ }^{1,2}$ The hydrodesulfurization (HDS) is a traditional method which is widely employed in industry. However, there are some disadvantages associated with HDS such as the harsh operation conditions (350 400 ${ }^{\circ} \mathrm{C}, 30 \sim 100$ bar hydrogen pressure), requirement of expensive catalysts, and the ineffectiveness to remove the cyclic 
sulfur compounds (S-compounds), ${ }^{3-5}$ which bring challenges to the HDS and give rise to the exploration and adoption of some alternative desulfurization methods. Among those, oxidative desulfurization (ODS) using ionic liquids (ILs) ${ }^{12-14}$ is more competitive based on the advantageous features of ILs i.e., excellent catalytic and extractive properties, and effectiveness of this method to remove those HDS-immune cyclic S-compounds in diesel fuel under the mild conditions. ${ }^{15-17}$

Although, ODS has good desulfurization performance for some model diesel fuel, ${ }^{18-20}$ it experiences difficulty at reducing the sulfur content (S-content) to a desirable level such as less than $10 \mathrm{ppm}$ for the real fuel oils, as reported in the previous literatures ${ }^{1,17,21,22}$ enlisted in Table 1 . In practice, we have used a desulfurization method, ${ }^{18-20}$ i.e., coupled oxidation-extraction desulfurization, which involves the ODS using ILs as both extractants and catalysts with $30 \mathrm{w} \%$ of $\mathrm{H}_{2} \mathrm{O}_{2}$ as oxidant followed by EDS using a solvent. ${ }^{17,23-26}$ This method can effectively desulfurize the diesel fuels and achieve the desirable S-content level (less than 10ppm) according to the stringent legislation. ${ }^{1,17,27}$ For example, in our previous work, ${ }^{24}$ we observed the S-content of real FCC diesel fuel decreased from 224.6 ppm to 37.4 ppm with $83.3 \%$ S-removal efficiency after ODS by $\left[\mathrm{C}_{1}\right.$ pyr $] \mathrm{Cl} / \mathrm{ZnCl}_{2}$; then the S-content decreased to $5.3 \mathrm{ppm}$ with $97.6 \%$ S-removal efficiency when used furfural as extractive reagent. We also observed the reduction in S-content of FCC diesel fuel from initial of $150 \mathrm{ppm}$ to $8.1 \mathrm{ppm}$ as a result of ODS by $\left[\left(\mathrm{CH}_{2}\right)_{4} \mathrm{SO}_{3} \mathrm{HMIm}\right][\mathrm{Tos}]$ and subsequent EDS by DMF. ${ }^{23}$ Moreover, the regeneration and recyclability of ILs and solvents can easily be achieved with a negligible loss in the activity. ${ }^{23}$ Therefore, coupled oxidation-extraction desulfurization can be regarded as one of the effective methods of desulfurization, which presents a good industrial prospect.

However, just use the experimental investigations are limited to develop sufficient data which may be helpful for designing an industrial-scale process. Therefore, the process simulation using the Aspen Plus is a promising way to develop a detailed insight into a design and development of a process. ${ }^{28,29}$ Recently, a few studies have been reported which employed the Aspen Plus to simulate the desulfurization process by ILs. ${ }^{30-33}$ For example, Nancarrow et al., ${ }^{32}$ used Aspen Plus to perform the process simulation and optimization of an industrial EDS with the $\left[\mathrm{C}_{\mathrm{n}} \operatorname{mim}\right]\left[\mathrm{NTF}_{2}\right]$ 
series of ILs, and observed that such IL-based extraction as an intermediate treatment can reduce the S-content from 7000ppm to $50 \mathrm{ppm}$. Song et al., ${ }^{33}$ employed Aspen Plus to identify the performance of the top ILs as extractants in EDS of the model gasoline fuel and observed that proposed technique can be easily extended to screen the favorable ILs for other practical applications of extraction. However, the studies reported so far were mostly based on some universal desulfurization methods (such as EDS or ODS) with simple components of model fuel oil. To our knowledge, the coupled oxidation-extraction desulfurization for the diesel fuel composed of complex components (in order to unlimited access to real diesel) needs to be studied with the aid of Aspen Plus.

In this work, a coupled oxidation-extraction desulfurization process is designed and simulated as shown in Figure 1 , wherein $\left[\mathrm{C}_{1}\right.$ pyr $] \mathrm{H}_{2} \mathrm{PO}_{4}$ is employed in the ODS process followed by using DMF in the EDS process. The main objectives of this study are (i) to propose and design an industrial-scale oxidation-extraction desulfurization process, (ii) to obtain the optimal operating conditions, hence to enable the simulation and optimization of this process, and (iii) to verify the experimental results and evaluate the feasibility to scale-up this technology.

\section{Methodology}

\section{The selection of desulfurization agent and diesel oil}

$\left[\mathrm{C}_{1}\right.$ pyr $] \mathrm{H}_{2} \mathrm{PO}_{4}$, which has smaller mutual solubility with fuel oil and was a good candidate solvent in desulfurization according to our previous works, ${ }^{34,35}$ is selected in the ODS process. DMF is selected as extractant to be used in subsequent EDS process, which can serve as perfect extractant in the EDS as reported in our previous works.

The diesel fuel is composed of 37 components (enlisted in Table 2) based on the straight-run diesel oil supplied by SINOPEC Beijing Yanshan Petrochemical Co., Ltd. Benzothiophene (BT) and dibenzothiophene (DBT) are selected as representative S-compounds and the original S-content is $224.12 \mathrm{ppm}$ (mass ratio).

\section{Properties of ILs and NRTL model}


In this study, simulation is performed with Aspen Plus V8.4. The parameters of ILs (such as critical parameters, saturated vapor pressure parameters, heat capacity, density, and molecular weight) are calculated by the Modified Lydersen-Joback-Reid. ${ }^{36-41}$ The group contribution values in the Modified Lydersen-Joback-Reid Method are enlisted in Table S1 and the formulas to calculate the parameters of ILs are given in Table S2. The NRTL model is selected as the thermodynamic model within Aspen Plus. COSMO-RS ${ }^{33-35}$ is used to calculate LLE data of the IL-based systems and the multiple interaction parameters of NRTL model are regressed from the LLE data predicted by COSMO-RS.

\section{COSMO-RS calculation}

COSMO-RS ${ }^{42,43}$ is based upon the information that is evaluated by quantum chemical methods. The quantum chemical basis of COSMO-RS is COSMO, which was computed by the quantum chemical program packages such as Turbomole, DMOL3 and Gaussian. TZVPD, TZVP, SVP and DNP basis set were used for this quantum calculation. COSMO supposes that molecules are surrounded by a virtual conductor environment and the interactions take place on segments of this perfect/ideal conductor interface taking into account the electrostatic screening and the backpolarization of the solute molecule. The current COSMO database already covers the screening charge density distributions ( $\sigma$-profiles) of thousands of conventional solvents and most of the reported cations and anions of ILs. The software package COSMOthermX (Version C30_1301) based on COSMO-RS allows for the thermodynamic calculations. In this work, the LLE calculations are performed using the BP_TZVP_C30_1301 parametrization. It should be mentioned that in the COSMO-RS calculation, ILs are treated as electro-neutral mixtures of separated cations and anions. The $\sigma$-profiles of the involved cations and anions of ILs, as well as the conventional compounds are directly taken from the standard database of the software. The $\sigma$-profiles of new compounds can be conveniently obtained from standard quantum chemical DFT calculations, which used in the geometry optimization.

There are two steps in COSMO-RS calculation: ${ }^{42,43} 1$ ) the $\sigma$-profiles of components are obtained by quantum chemical calculations; 2) the chemical potential $\left(\mu_{s}(\sigma)\right)$ of component is quantified through the statistical thermodynamics treatment of molecular interactions based on the obtained $\sigma$-profiles given by eq 1 : 


$$
\mu_{s}(\sigma)=-\frac{R T}{a_{e f f}} \ln \left[\int p_{s}\left(\sigma^{\prime}\right) \exp \left(\frac{a_{e f f}}{R T}\left(\mu_{s}\left(\sigma^{\prime}\right)-\left(\mathrm{E}_{v d W}\left(\sigma, \sigma^{\prime}\right)+\mathrm{E}_{H B}\left(\sigma, \sigma^{\prime}\right)+\mathrm{E}_{M F}\left(\sigma, \sigma^{\prime}\right)\right) / a_{e f f}\right)\right) \mathrm{d} \sigma^{\prime}\right]
$$

In eq $1, a_{\text {eff }}$ is the effective contact area between two surface segments and $\mathrm{P}_{S}(\sigma)$ is the surface screening charge distribution of the whole system.

The LLE data can be determined with $\mu_{s}(\sigma)$. LLE calculation is explained with a liquid system of phase 1 and phase 2 as an example. The compounds distributed in phase 1 and phase 2 according to the partition equilibrium constants $\left(K_{i}\right)$ :

$$
K_{i}=\exp \left(\frac{u_{i}^{1}-u_{i}^{2}}{R T}\right)
$$

where $\mu_{\mathrm{i}}{ }^{1}$ and $\mu_{\mathrm{i}}^{2}$ are the chemical potential of compound $\mathrm{i}$ in phase 1 and phase 2 , respectively.

In order to validate the LLE data calculated by COSMO-RS is reliable for IL-based desulfurization system, we have compared the desulfurization results obtained through Aspen plus simulation (LLE data calculated by COSMORS, then regressed the NRTL parameters from the LLE data) with some experimental results. The results (Table S3) indicate that the COSMO-RS can calculate the LLE data of the IL-based system qualitatively and in many cases acceptable quantitatively, which have also been proved by other researches. ${ }^{44-47}$

\section{Process simulation}

Parameters of IL: the parameters of $\left[\mathrm{C}_{1}\right.$ pyr $] \mathrm{H}_{2} \mathrm{PO}_{4}$ which need to be specified in Aspen Plus for the IL-based process are shown in Table S4 $\sim$ Table S6. The multiple interaction parameters of the IL-based systems are listed in Table S7. The flowsheet representing the coupled oxidation-extraction desulfurization process is depicted in Figure 2, where the reactor, extractor, evaporator, mixer, compressor, condenser and filter are modeled by the RYield block, Extract block, Flash block, Mixer block, Comp block, Heater block, and Split block, respectively.

ODS process: as shown in the Figure 2, $\mathrm{IL}, 30 \% \mathrm{H}_{2} \mathrm{O}_{2}$ and $10,000 \mathrm{~kg} / \mathrm{hr}$ of diesel fuel are fed in the reactor (B1). After complete reaction, the extracted mixture (S4) is allowed to settle into the decanter (B9), where the two distinct phases i.e., IL phase (S5) and diesel fuel phase (S6) are formed based on their density difference. 
EDS process: the diesel fuel (S6) is introduced into the extractor (B3) at its bottom, while a certain amount of DMF (S8) is fed from the top of the extractor (B3). The diesel fuel product (S10) is obtained from the top of the extractor.

Regeneration process of ILs: regenerations of the used IL (S5) is performed by dilution with water (S7) in the mixer (B10) because it is hydrophilic while S-compounds are hydrophobic. The mixture (S19) undergoes the filtration in the filter (B11), whose downstream (S21) enters the flash (B12) where simple distillation occurs. The regenerated IL (S23) is then recycled through the cooler (B13), to bottom of the reactor column (B1), together with required amount of fresh IL (S3).

Regeneration process of extractants: the used DMF (S11) is dealt in two evaporators (B4 and B5) for its regeneration. After, the regenerated DMF is then recycled through the compressor (B6), condenser (B7), and mixer (B8) into extraction column (B3) from the top, together with required amount of fresh DMF (S9).

\section{Results and Discussion}

A sensitivity analysis of operating parameters is performed for optimizing the process conditions of the ODS, EDS, regeneration process of ILs and extractants, respectively.

\section{IL Feed Rate}

The influence of mass-based IL-oil ratio (S/F) on the mass flow of BT and DBT for $\left[\mathrm{C}_{1}\right.$ pyr $] \mathrm{H}_{2} \mathrm{PO}_{4}$ in the ODS process (B1) is determined and plotted in Figure 3. As plotted in Figure 3, when the IL-to-oil ratio increases from 0.5 to 1, the mass flow of BT and DBT notably decreases, whereas beyond this value, there is insignificant decrease in the mass flow of the S-compounds. The influence of the IL-to-oil ratio on the yield of diesel fuel is given in Figure 4, which shows that the yield of diesel fuel decreases linearly with the increase of the IL-to-oil ratio from 0.5 to 3 . For example, the mass flow of BT and DBT decreases from $9.09 \mathrm{~kg} / \mathrm{h}$ to $3.72 \mathrm{~kg} / \mathrm{h}$ and $10.01 \mathrm{~kg} / \mathrm{h}$ to $4.20 \mathrm{~kg} / \mathrm{h}$, respectively, while the efficiency of diesel yield declines from $95.25 \%$ to $88.86 \%$ when the IL-to-oil ratio increases from 0.5 to 1 . The IL-oil ratio of 1 is selected by comprehensive consideration of the S-content and diesel yield from the industrial 
application view point. There is mutual solubility between IL and diesel fuel, which can lead to the loss of diesel fuel.

5, 34 The loss can be minimized by selecting more suitable ILs characterized with little or no mutual solubility with diesel fuel, as well as, recycling the diesel during the IL regeneration process.

It should be pointed out that, the RYield block is used for the ODS process and the reaction is not actually simulated because it is difficult to obtain accurate reaction kinetics as the composition of diesel is complex and the products is uncertain.

\section{Organic solvent Feed Rate}

As shown in Figure 3, the Non-thiophene S-compounds (dimethyl sulfide and ethanethiol) are completely removed in ODS process (B1), only the remaining BT and DBT are considered for removal in the EDS process (B3).

The influence of the mass-based solvent-to-oil ratio (S/F) on the mass flow of BT and DBT for the selected DMF in EDS process is determined and plotted in Figure 5. It can be seen that, when the solvent-to-feed ratio increases from 0.5 to 1 , the mass flow of BT and DBT notably decreases, whereas, after that both decrease slowly and finally become invariant. The influence of the solvent-to-feed ratio on the yield of diesel fuel is shown in Figure 6. As shown, the yield of diesel fuel decreases linearly with the increasing the solvent-to-feed ratio from 0.5 to 3 . For example, the mass flow of BT and DBT decreases from $0.02 \mathrm{~kg} / \mathrm{h}$ to $0 \mathrm{~kg} / \mathrm{h}$ and $0.11 \mathrm{~kg} / \mathrm{h}$ to $0.02 \mathrm{~kg} / \mathrm{h}$, respectively, while the efficiency of the diesel yield decreases from $100 \%$ to $94.45 \%$ when the solvent-to-feed ratio increases from 0.5 to 1 . Therefore, the solvent-to-feed ratio of 1 can be selected by comprehensive consideration of the of S-content and diesel yield.

\section{IL Regeneration}

The requirement of the IL-regeneration process (B12) is to remove the water in the IL-mixture stream (S21) into the S23 stream (Figure 2) since the compounds of sulfone is hardly soluble in water and mostly removed through the filtration (B11) process. The influence of operating temperature and pressure on the removal rate of water is investigated and the results are plotted in Figure 7. 
The operating pressure and temperature have different effect on removal rate of water from $\left[\mathrm{C}_{1} \mathrm{pyr}\right] \mathrm{H}_{2} \mathrm{PO}_{4}$ in different manner, e.g., the removal rate of water increases with increasing of the temperature but with decreasing of the pressure. For instance, when the flash (B12) is operated at $0.5 \mathrm{bar}, 0.8 \mathrm{bar}$, and $1 \mathrm{bar}$, the required temperature for regeneration of $\left[\mathrm{C}_{1}\right.$ pyr $] \mathrm{H}_{2} \mathrm{PO}_{4}$ are $114{ }^{\circ} \mathrm{C}, 126^{\circ} \mathrm{C}$, and $138^{\circ} \mathrm{C}$, respectively. To avoid the utilization of vacuum pump as well as to save operating cost, the atmospheric distillation at operating conditions of 1 bar and $138^{\circ} \mathrm{C}$ is preferred in the IL regeneration process.

\section{Organic solvents regeneration}

The regeneration of DMF, where two flash column (B4 and B5) are employed, needs to remove the impurities of S-compounds in order to ensure the regenerated DMF retains the original extractive performance. The first flash column (B4) is operated under the high pressure and low temperature, whereas, the second flash column (B5) is operated under the low pressure and high temperature.

As shown in Figure 8, there is a general increasing trend of mass flow of the total material, DMF, and the other material with the increasing of temperature. Moreover, when the temperature increases from $120^{\circ} \mathrm{C}$ to $180^{\circ} \mathrm{C}$, the mass flow of the total material and DMF increase gradually, after that the mass flow of both increases notably; while the mass flow of the other material increases slowly with the temperature. Since the loss rate of DMF increases greatly above the $180^{\circ} \mathrm{C}$, thus, the first flash column is operated under $180^{\circ} \mathrm{C}$ in order to minimize the loss of DMF.

The purpose of the second flash column (B5) is to vaporize the DMF for the separation of other impurities. The effect of temperature and pressure on the mass flow and mass fraction of distilled DMF are shown in Figure 9 and Figure 10, respectively. It can be indicated that the mass flow and mass fraction of the distilled DMF increase rapidly from $26.02 \mathrm{~kg} / \mathrm{h}$ to $12171.02 \mathrm{~kg} / \mathrm{h}$ and $76.51 \%$ to $96.03 \%$, respectively, when the temperature increases from $192{ }^{\circ} \mathrm{C}$ to $198^{\circ} \mathrm{C}$. Subsequently, with the further increase in the temperature, the mass flow of DMF remains the same while the mass fraction of DMF decrease and then stay the same. Therefore, the operating temperature of the second flash column (B5) is set at $198{ }^{\circ} \mathrm{C}$. As shown in Figure 10, when the operating pressure increases from 0.6 bar to 0.8 bar at 
$198^{\circ} \mathrm{C}$, the mass flow of DMF increases rapidly from $0 \mathrm{~kg} / \mathrm{h}$ to $11988.33 \mathrm{~kg} / \mathrm{h}$ whereas after that the mass flow remain the same. The mass fraction of DMF decreases with the pressure. Thus, the operating pressure is set at 0.8 bar.

\section{Simulation results}

The results of the coupled oxidation-extraction desulfurization by $\left[\mathrm{C}_{1} \mathrm{pyr}\right] \mathrm{H}_{2} \mathrm{PO}_{4}$ and $\mathrm{DMF}$ for the diesel fuel under the optimal operating conditions (B1 and B3: $180^{\circ} \mathrm{C}$, 1 bar, IL-to-oil ratio is 1 , DMF-to-oil ratio is 1 ; $\mathrm{B} 4: 150{ }^{\circ} \mathrm{C}$, 1bar; B5: $198^{\circ} \mathrm{C}, 0.8$ bar; B12: $138^{\circ} \mathrm{C}, 1$ bar) are shown in Table 3 . The obtained results clearly reveal that this method can effectively remove both the non-thiophene S-compounds such as ethanethiol and dimethyl sulfide, as well as the thiophene-sulfides such as benzothiophene and diphenylthiophene. For instance, the S-removal efficiency of ethanethiol, dimethyl sulfide, benzothiophene and diphenylthiophene can be obtained of $98.7 \%, 98.98 \%, 99.24 \%$ and $99.46 \%$, respectively. It is also found that the S-content of the diesel fuel remarkably reduced from 224.12 ppm to 8.32 ppm (total desulfurization efficiency is $96.29 \%$ ) and meet the requirement of stringent legislation of less than 10ppm. Aspen Plus has proved to be useful to study the industrial-scale coupled oxidation-extraction desulfurization method. It is also observed that, this technique as an alternative to HDS, can produce ULSD with the requirement of feasible and moderate conditions.

\section{Comparison of the proposed process with $\mathrm{HDS}$}

Table 4 illustrates the comparative study of the coupled oxidation-extraction desulfurization method and the traditional HDS from the economic point of view. For both of the processes, mainly, operating cost is a critical economic consideration. For HDS, the capital investment includes the retrofitting to enable existing equipment for achieving the ULSD standard, which significantly increases energy requirement as well as the consumption of $\mathrm{H}_{2} .{ }^{30}$

32 The energy requirement and solvent consumption of ILs-based process are summarized in Table 5. The energy consumed in the regeneration of ILs and DMF with a capacity of $10000 \mathrm{~kg} / \mathrm{h}$ diesel fuel are about $8985.24 \mathrm{~kW}$ and $2138.54 \mathrm{~kW}$, respectively. In case of this method, regeneration of ILs and solvents mainly contributes in the total operating cost. 
Compared to HDS, the IL-based desulfurization method can be conducted under milder conditions with simpler equipment. This technology has significant advantages in terms of environmental impact and process safety, and as legislation becomes more stringent in future years, the present method will continue to become more critical in technology selection.

\section{Conclusion}

This work is based on simulating a coupled oxidation-extraction desulfurization process which is used to desulfurize the diesel fuel composed of 37 components. This method involves two steps, first ODS by $\left[\mathrm{C}_{1} \mathrm{pyr}\right] \mathrm{H}_{2} \mathrm{PO}_{4}$ as an extractant as well as catalyst, second EDS by DMF as extracting agent. The industrial-scale of the coupled desulfurization processing of ULSD has been examined via the Aspen Plus simulation and the optimization of various operating conditions, i.e., IL-to-oil ratio, DMF-to-oil ratio, and operating temperature and pressure. Subsequently, the process is compared economically with the conventional HDS. The main conclusions drawn from this study are: 1) the S-content in the diesel fuel was reduced to only $8.32 \mathrm{ppm}$ from initial of $224.12 \mathrm{ppm}$ with $96.29 \%$ S-removal efficiency under the optimized conditions, which indicated that the coupled oxidation-extraction desulfurization method can achieve specifications of ULSD and provide technically feasible and moderate conditions as an alternative to HDS technology; 2) the regeneration of ILs and solvents mainly contributes in the total operating cost in this new technology, and the energy consumption of this process is higher than that in HDS-based process; 3) there is mutual solubility between diesel and extraction solvent and the loss of diesel is mainly because a part of diesel is dissolved into the extraction solvent, which is one of the bottlenecks restricting the industrialization of IL-desulfurization. Therefore, in our next research, we will continue to investigate the IL-desulfurization technology and develop a suitable method to regenerate and recycle the loss diesel. However, expected drop in cost of regeneration of diesel and extraction solvent in future combined with timely constricting environmental legislation and improved performance of process due to continuous research in this field, the proposed technique may become a promising option to replace HDS.

\section{Acknowledgements}


This work was financially supported by the National Science Foundation of China (21176021, 21276020, 2187081257). We extend our appreciation to the Deanship of Scientific Research at King Saud University for funding the work, through Research Group Project No. RG-1436-026.

\section{References}

1. Nie, Y.; Dong, Y. X.; Bai, L.; Dong, H. F.; Zhang, X. P. Fast oxidative desulfurization of fuel oil using dialkylpyridinium tetrachloroferrates ionic liquids. Fuel 2013, 103, 997-1002.

2. Wagle, D. V.; Zhao, H.; Deakyne, C. A.; Baker, G. A. Quantum Chemical Evaluation of Deep Eutectic Solvents for the Extractive Desulfurization of Fuel. ACS Sustainable Chem. Eng. 2018, 6, 7525-7531.

3. Ibrahim, J. J.; Gao, S. R.; Abdeltawab, A. A.; Al-Deyab, S. S.; Yu, G. R.; Chen, X. C.; Yong, X. Y. Extractive desulfurization of fuel oils with dicyano(nitroso)methanide-based ionic liquids. Sep. Sci. Tech. 2015, 50, 11661174.

4. Abro, R.; Abdeltawab, A. A.; Al-Deyab, S. S.; Yu, G. R.; Qazi, A. B.; Gao, S. R.; Chen, X. C. A review for extractive desulfurization of fuel oils using ionic liquids. $R S C A d v . \mathbf{2 0 1 4}, 4,35302-35317$.

5. Gao, S. R.; Chen, X. C.; Abro, R.; Su, Z.; Abdeltawab, A. A.; Al-Deyab, S. S.; Yu, G. R. Mutual solubility of acidic ionic liquid and model gasoline of $\mathrm{n}$-octane +1 -octene + toluene. J. Taiwan Inst. Chem. E. 2016, 69, 7884.

6. Zhao, R. J.; Wang, J. L.; Zhang, D. D.; Sun, Y. H.; Han, B. X.; Tang, N.; Zhao, J. H.; Li, K. X. Deep Catalytic Oxidative Desulfurization of Model Fuel Based on Modified Iron Porphyrins in Ionic Liquids: Anionic Ligand Effect. ACS Sustainable Chem. Eng. 2017, 5, 2050-2055.

7. Zhang, G.; Yu, F.; Wang. R. Research advances in oxidative desulfurization technologies for the production of low sulfur fuel oils. Petroleum \& Coal 2009, 51, 196-207.

8. Abro, R.; Gao, S. R.; Chen, X. C.; Yu, G. R.; Abdeltawab, A. A.; Al-Deyab, S. S. Oxidative Desulfurization of Gasoline by Ionic Liquids Coupled with Extraction by Organic Solvents. J. Braz. Chem. Soc. 2016, 26, 998-1006. 
9. Mei, H.; Mei, B. W.; Yen, T. F. A new method for obtaining ultra-low sulfur diesel fuel via ultrasound assisted oxidative desulfurization. Fuel 2003, 82, 405-414.

10. Bhutto, A. W.; Abro, R.; Gao, S. R.; Abbas, T.; SalemS, A. A.; Chen, X. C.; Yu, G. R. Oxidative desulfurization of fuel oils using ionic liquids: A review. J. Taiwan Inst. Chem. E. 2016, 62, 84-97.

11. Zhu, W. S.; Dai, B. L.; Wu, P. W.; Chao, Y. H.; Xiong, J.; Xun, S. H.; Li, H. P.; Li, H. M. Graphene-Analogue Hexagonal BN Supported with Tungsten-based Ionic Liquid for Oxidative Desulfurization of Fuels. ACS Sustainable Chem. Eng. 2015, 3, 186-194.

12. Zhao, H.; Baker, G. A.; Wagle, D. V.; Ravula, S.; Zhang, Q. Tuning Task-Specific Ionic Liquids for the Extractive Desulfurization of Liquid Fuel. ACS Sustainable Chem. Eng. 2016, 4, 4771-4780.

13. Endres, F. Ionic Liquids: Promising Solvents for Electrochemistry. Z. Phys. Chem. 2004, 218, 255-283.

14. Brennecke, J. F.; Maginn, E. J. Ionic Liquids: Innovative Fluids for Chemical Processing. AIChE J. 2001, 47, 2384-2389.

15. Asumana, C.; Yu, G. R.; Li, X.; Zhao, J. J.; Liu, G.; Chen, X. C. Extractive desulfurization of fuel oils with lowviscosity dicyanamide-based ionic liquids. Green Chem. 2010, 12, 2030-2037.

16. Yu, G. R.; Li, X.; Liu, X. X.; Asumana, C.; Chen, X. C. Deep desulfurization of fuel oils using low-viscosity 1ethyl-3-methylimidazolium dicyanamide ionic liquid. Ind. Eng. Chem. Res. 2010, 50, 2236-2244.

17. Chen, X. C.; Guan, Y. W.; Abdeltawab, A. A.; Al-Deyab, S. S.; Yuan, X. L.; Wang, C. Y.; Yu, G. R. Using functional acidic ionic liquids as both extractant and catalyst in oxidative desulfurization of diesel fuel: an investigation of real feedstock. Fule 2015,146, 6-12.

18. Zhu, W. S.; Li, H. M.; Jiang, X.; Yan, Y. S.; Lu, J. D.; Xia, J. X. Oxidative Desulfurization of Fuels Catalyzed by Peroxotungsten and Peroxomolybdenum Complexes in Ionic Liquids. Energy \& Fuels 2007, 21, 2514-2516.

19. Zhang, M.; Zhu, W. S.; Xun, S. H.; Li, H. M.; Gu, Q. Q.; Zhao, Z.; Wang, Q. Deep Oxidative Desulfurization of Dibenzothiophene with POM-Based Hybrid Materials in Ionic Liquids. Chem. Eng. J. 2013, 220, 328-336.

20. Li, F. T.; Kou, C. G.; Sun, Z. M.; Hao, Y. J.; Liu, R. H.; Zhao, D. S. Deep Extractive and Oxidative Desulfurization of Dibenzothiophene with $\mathrm{C}_{5} \mathrm{H}_{9} \mathrm{NO} \cdot \mathrm{SnCl}_{2}$ Coordinated Ionic Liquid. J. Hazard. Mater. 2012, 205, 164-170.

21. Chen, X. C.; Song, D. D.; Asumana, C.; Yu, G. R. Deep oxidative desulfurization of diesel fuels by Lewis acidic ionic liquids based on 1- n-butyl-3-methylimidazolium metal chloride. J. Mol. Catal. A: Chem. 2012, 359, 8-13. 
22. Zhao, D. S.; Sun, Z. M.; Li, F. T.; Shan, H. D. Optimization of oxidative desulfurization of dibenzothiophene using acidic ionic liquid as catalytic solvent. J. Fuel Chem. Technol. 2009, 37, 194-198.

23. Gao, S. R.; Li, J. Y.; Chen, X. C.; Abdeltawab, A. A.; Yakout, S. M.; Yu, G. R. A Combination Desulfurization Method for Diesel Fuel: Oxidation by Ionic Liquid with Extraction by Solvent. Fuel 2018, 2, $123-128$.

24. Chen, X. C.; Guo, H. S.; Abdeltawab, A. A.; Guan, Y. W.; Al-Deyab, S. S.; Yu, G. R.; Yu, L. BrÖnsted-Lewis acidic ionic liquids and application in oxidative desulfurization of diesel. Fuel 2015, 29, 2998-3003.

25. Lo, W. H.; Yang, H. Y.; Wei G. T. One-pot desulfurization of light oils by chemical oxidation and solvent extraction with room temperature ionic liquids. Green Chem. 2003, 5, 639-642.

26. Lu, L.; Cheng S. F.; Gao, J. B.; Gao G. H.; He, M. Y. Deep Oxidative Desulfurization of Fuels Catalyzed by Ionic Liquid in the Presence of $\mathrm{H}_{2} \mathrm{O}_{2}$. Energy \& Fuels 2007, 21, 383-384.

27. Sengupta, A.; Kamble, P. D.; Basu, J. K.; Sengupta, S. Kinetic study and optimization of oxidative desulfurization of benzothiophene using mesoporous titanium silicate-1 catalyst. Ind. Eng. Chem. Res. 2011, 51, 147-157

28. Ma, T.; Wang, J. X.; Du, Z. Z.; Abdeltawab, A. A.; Al-Enizi, A. M.; Chen, X. C.; Yu, G. R. A process simulation study of $\mathrm{CO}_{2}$ capture by ionic liquids. International Journal of Greenhouse Gas Control 2017, 58, $223-231$.

29. Bezzo, F.; Bernardi, R.; Cremonese, G.; Finco, M.; Barolo, M. Using process simulators for steady-state and dynamic plant analysis-An industrial case study. Chem. Eng. Res. Des. 2004, 82, 499-512.

30. Li, Z.; Xu, J.; Li, D.; Li, C. Extraction process of sulfur compounds from fuels with protic ionic liquids. $R S C A d v$. 2015, 5, 15892-15897.

31. Song, Z.; Zhang, C.; Qi, Z. W.; Zhou, T. Sundmacher K. Computer-aided design of ionic liquids as solvents for extractive desulfurization. AICHE J. 2018, 64: 11.

32. Nancarrow, P.; Mustafa, N.; Shahid, A.; Varughese, V.; Zaffar, U.; Ahmed, R.; Akther, N.; Ahmed, H.; AlZubaidy, I.; Hasan, S.; Elsayed, Y.; Sara, Z. Technical Evaluation of Ionic Liquid-Extractive Processing of Ultra Low Sulfur Diesel Fuel. Ind. Eng. Chem. Res. 2015, 54, 10843-10853.

33. Song, Z.; Zhou, T.; Zhang, C.; Qi, Z. W. Sundmacher K. Systematic Method for Screening Ionic Liquids as Extraction Solvents Exemplified by an Extractive Desulfurization Process. ACS Sustainable Chem. Eng. 2017, 5, $3382-3389$.

34. Gao, S. R.; Yu, G. R.; Abro, R.; Abdeltawab, A. A.; Al-Deyab, S. S.; Chen, X. C. Desulfurization of fuel oils: Mutual solubility of ionic liquids and fuel oils. Fuel 2016, 173, 164-171. 
35. Gao, S. R.; Chen, X. C.; Abro, R.; Abdeltawab, A. A.; Al-Deyab, S. S.; Yu, G. R. Desulfurization of fuel oil: conductor-like screening model for real solvents study on capacity of ionic liquids for thiophene and dibenzothiophene. Ind. Eng. Chem. Res. 2015, 54, 9421-9430.

36. Valderrama, J. O.; Forero, L. A.; Rojas, R. E. Critical Properties and Normal Boiling Temperature of Ionic Liquids. Update and a New Consistency Test. Ind. Eng. Chem. Res. 2012, 51, 7838-7844.

37. Rebelo, L. P.; Canongia Lopes, J. N.; Esperança, J. M. On the critical temperature, normal boiling point, and vapor pressure of ionic liquids. J. Phys. Chem. B 2005, 109, 6040-6043.

38. Simon, R. H. M. Estimation of critical properties of organic compounds by the method of group contributions. A. L. Lyderren. Engineering Experiment Station Report. AICHE J. 1956, 2, 12S-12S.

39. JOV, And W W S, JAL. Critical Properties, Normal Boiling Temperature, and Acentric Factor of Another 200 Ionic Liquids. Ind. Eng. Chem. Res. 2008, 47, 1318-1330.

40. Valderrama, J. O.; Sang, W. W.; Lazzus, J. A. Critical Properties, Normal Boiling Temperature, and Acentric Factor of Another 200 Ionic Liquids. Ind. Eng. Chem. Res. 2008, 47, 1318-1330.

41. Joback, K. G.; Reid, R. C. Estimation of pure-component properties from group-contributions. Chem. Eng. Commun. 1987, 57, 233-243.

42. Eckert, F.; Klamt, A. Fast solvent screening via quantum chemistry: COSMORS approach. AIChE J. 2002, 48, $369-385$.

43. Eckert, F.; Klamt, A. COSMOtherm, version C3.0; COSMOlogic GmbH \& Co. KG: Leverkusen, Germany 2013.

44. Ferreira, A. R.; Freire, M. G.; Ribeiro, J. C.; Lopes, F. M.; Crespo, J. G.; Coutinho, J. A. P. Overview of the liquidliquid equilibria of ternary systems composed of ionic liquid and aromatic and aliphatic hydrocarbons, and their modeling by COSMO-RS. Ind. Eng. Chem. Res. 2012, 51, 3483-3507.

45. Ferreira, A. R.; Freire, M. G.; Ribeiro, J. C.; Lopes, F. M.; Crespo, J. G.; Coutinho, J. A. P. An overview of the liquid-liquid equilibria of (ionic liquid + hydrocarbon) binary systems and their modeling by the conductor-like screening model for real solvents. Ind. Eng. Chem. Res. 2011, 50, 5279-5294.

46. Anantharaj, R.; Banerjee, T. Aromatic sulfur-nitrogen extraction using ionic liquids: Experiments and predictions using an a priori model. AIChE J. 2013, 59, 4806-4815. 
47. Ferreira, A. R.; Freire, M. G.; Ribeiro, J. C.; Lopes, F. M.; Crespo, J. G.; Coutinho, J. A. P. Overview of the liquidliquid equilibria of ternary systems composed of ionic liquid and aromatic and aliphatic hydrocarbons, and their modeling by COSMO-RS. Ind. Eng. Chem. Res. 2012, 51, 3483-3507. 


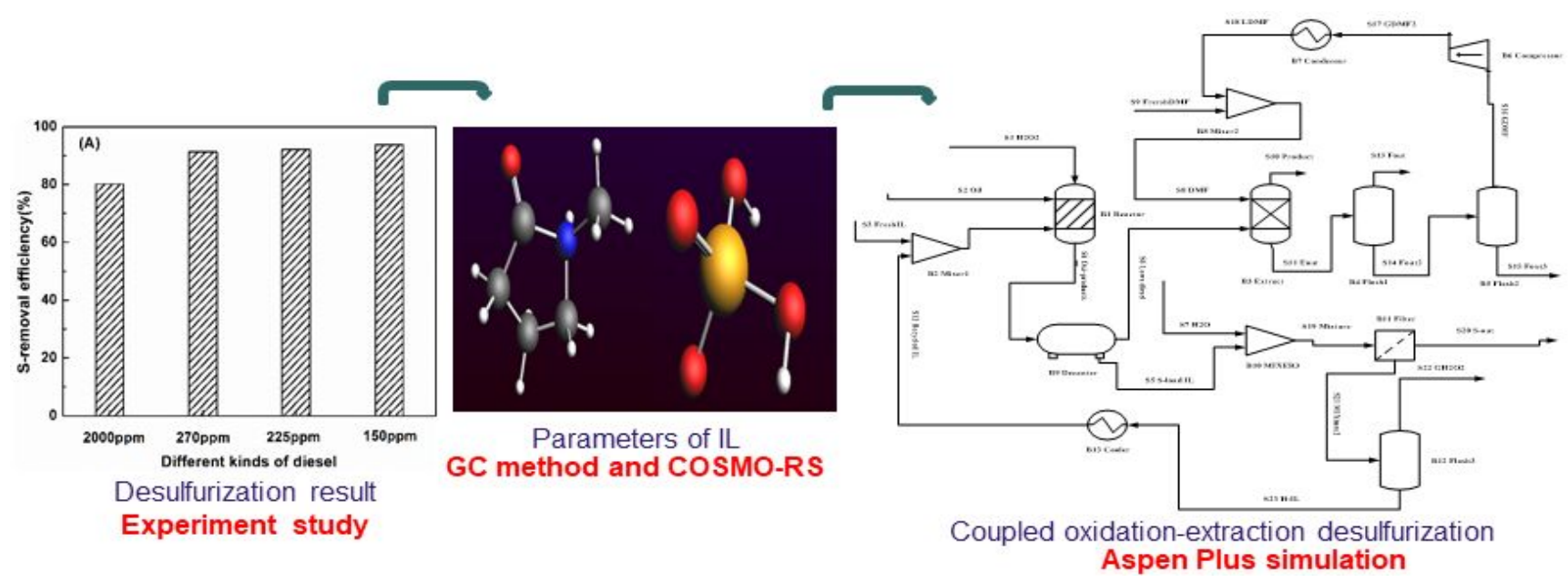

Fig. 1. Schematic diagram of the coupled oxidation-extraction desulfurization in this manuscript. 


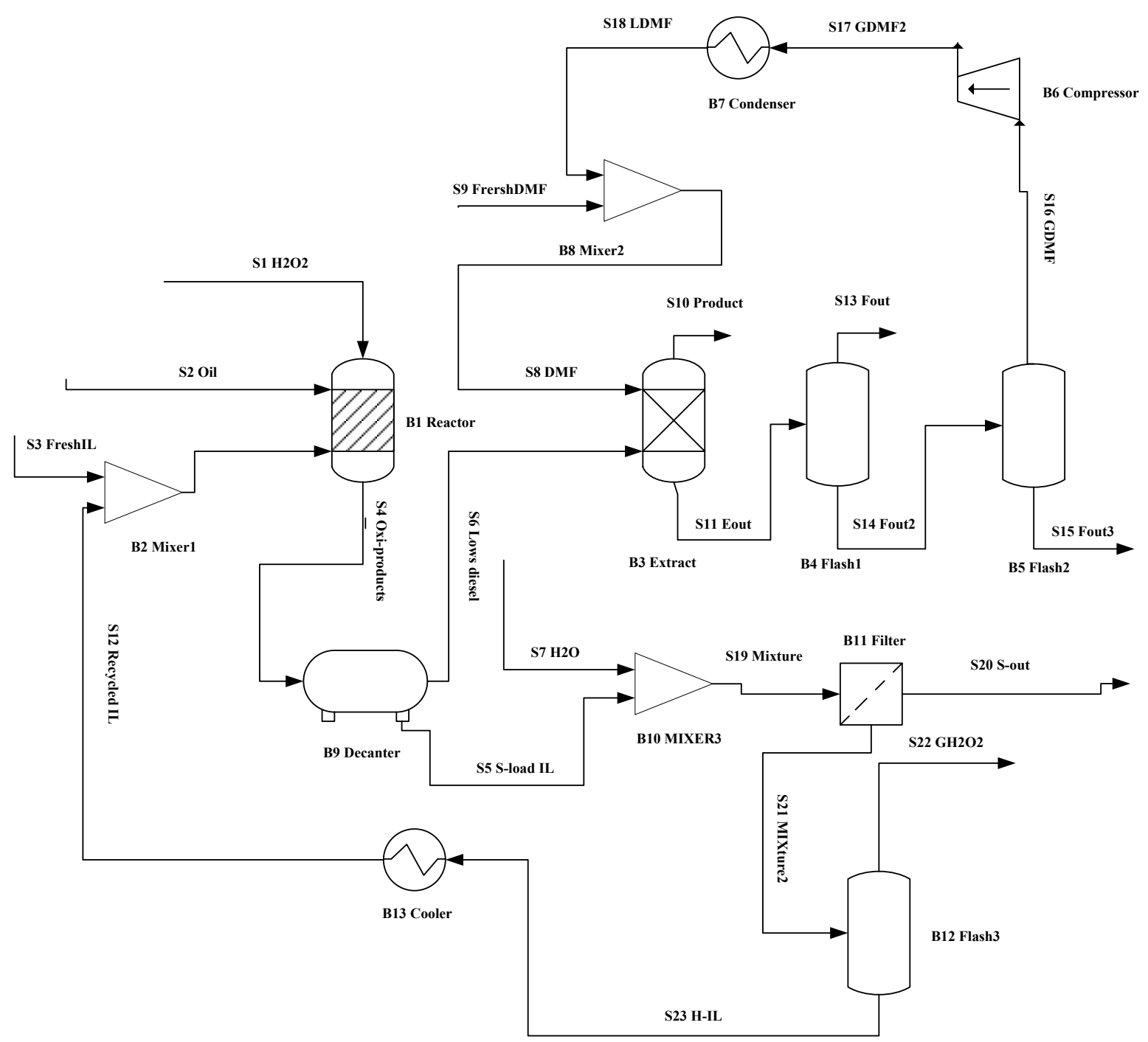

Fig. 2. Flow chart of the coupled oxidation-extraction desulfurization 


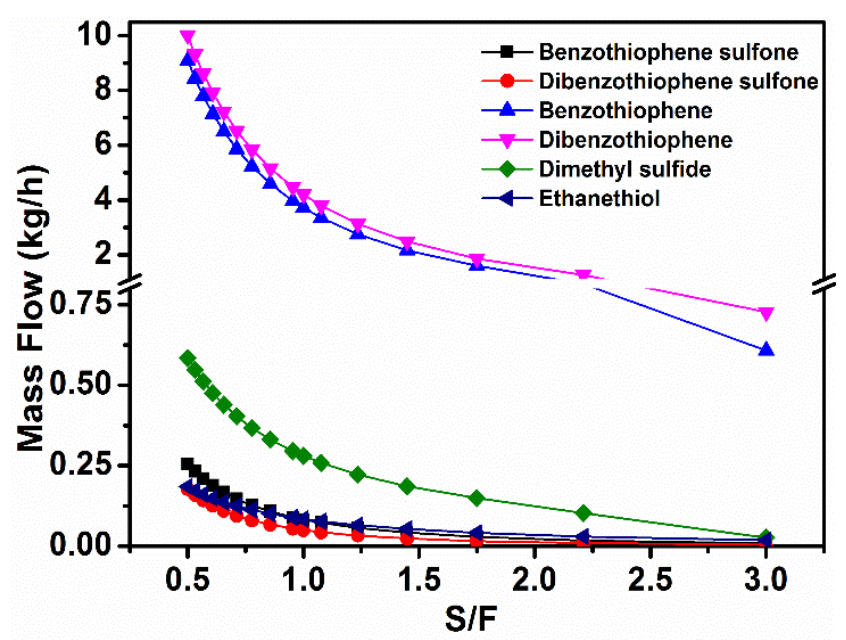

Fig. 3. Influence of the mass ratio $\left[\mathrm{C}_{1} \mathrm{pyr}\right] \mathrm{H}_{2} \mathrm{PO}_{4} /$ diesel $(\mathrm{S} / \mathrm{F})$ on the mass flow of S-compounds 


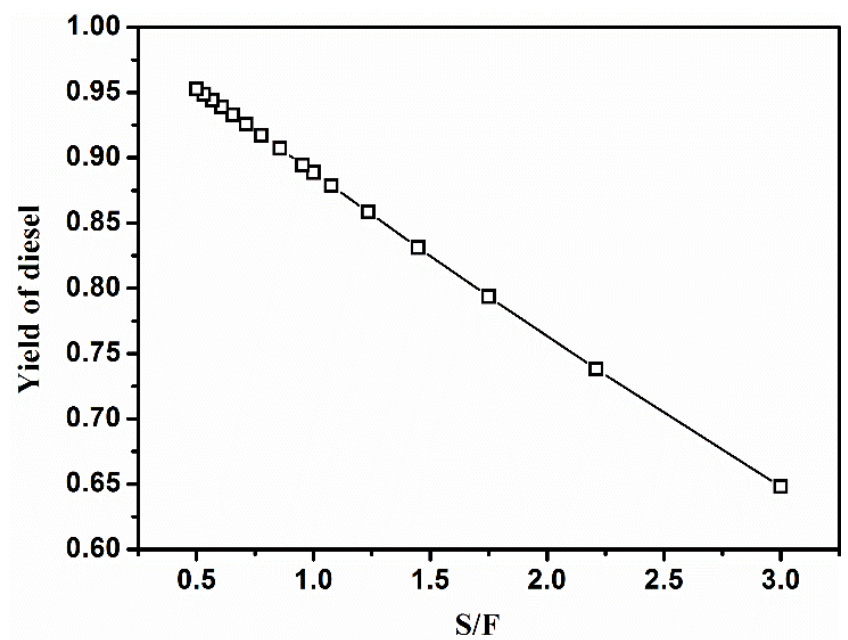

Fig. 4. Influence of the mass ratio $\left[\mathrm{C}_{1}\right.$ pyr $] \mathrm{H}_{2} \mathrm{PO}_{4} /$ diesel $(\mathrm{S} / \mathrm{F})$ on the yield of diesel 


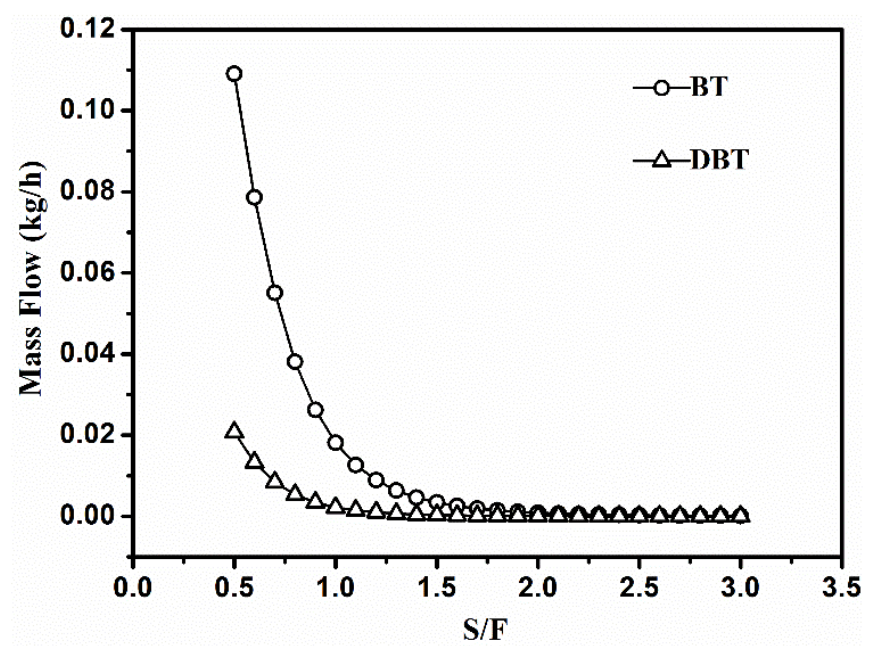

Fig. 5. Influence of the mass ratio DMF/diesel (S/F) on the mass flow of S-compounds 


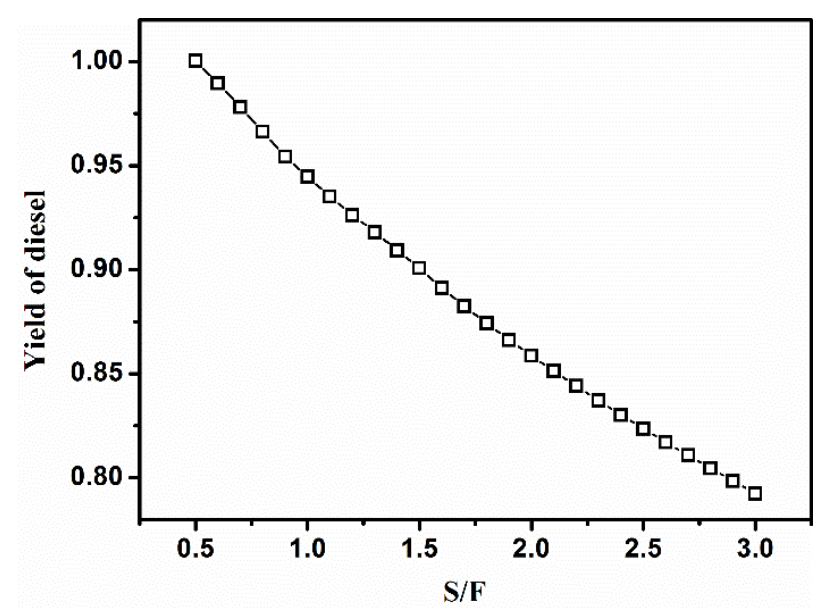

Fig. 6. Influence of the mass ratio DMF/diesel (S/F) on the yield of diesel 


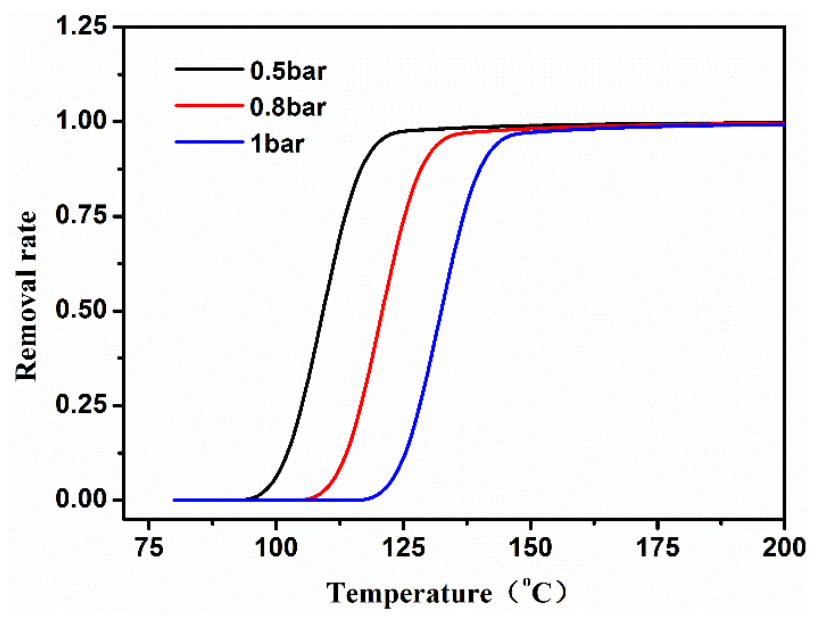

Fig. 7. Influence of temperature and pressure on the removal rate of water 


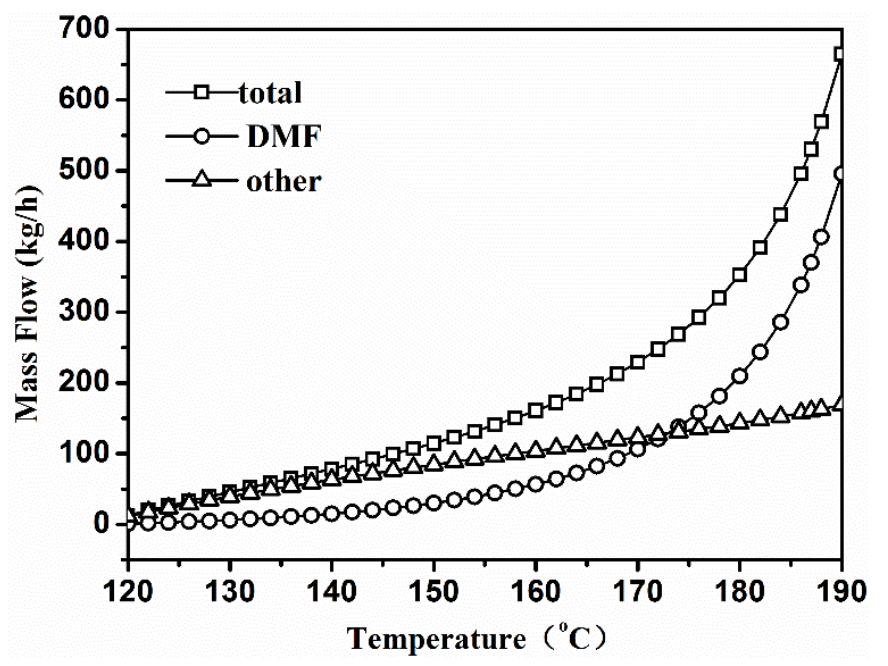

Fig. 8. Effect of temperature on the first flash of DMF 


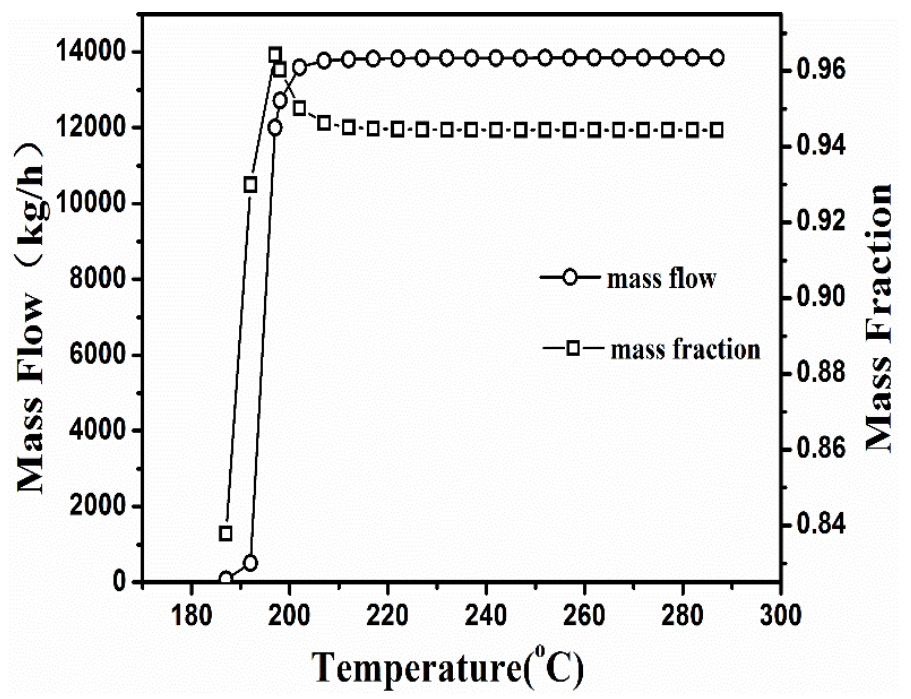

Fig. 9. Effect of temperature on second flash of DMF 


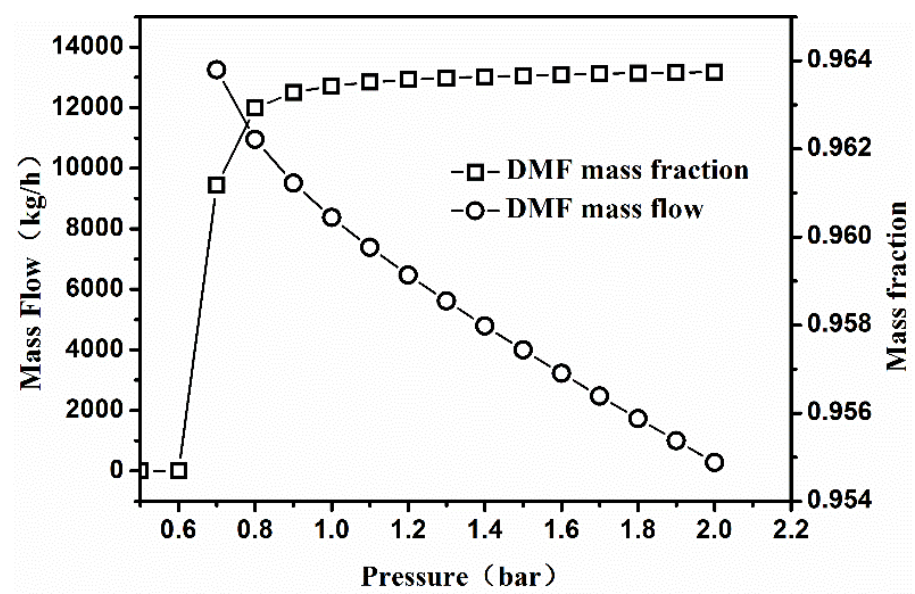

Fig. 10. Effect of pressure on the second flash of DMF 
Table 1. Oxidative desulfurization of real oils by ILs.

\begin{tabular}{|c|c|c|c|c|}
\hline ILs & $\begin{array}{l}\text { Real oil } \\
\text { (initial S-content) }\end{array}$ & S-removal efficiency & Reaction condition & Ref. \\
\hline$\left[\mathrm{C}_{8}^{3} \mathrm{MPy}\right] \mathrm{FeCl}_{4}$ & $\begin{array}{l}\text { gasoline } \\
(468 \mathrm{ppm})\end{array}$ & $44.2 \%$ & $\begin{array}{l}\mathrm{T}, 298 \mathrm{~K} ; \mathrm{t}, 30 \mathrm{~min} ; \text { mass ratio of IL/Oil, } \\
\text { 1/3; O/S, } 6\end{array}$ & [1] \\
\hline$\left[\mathrm{C}_{4} \mathrm{mim}\right] \mathrm{Cl} / 3 \mathrm{ZnCl}_{2}$ & $\begin{array}{l}\text { FCC diesel fuel } \\
(460 \mathrm{ppm})\end{array}$ & $63.5 \%$ & $\begin{array}{l}\mathrm{T}, 318.15 \mathrm{~K} ; \mathrm{t}, 3 \mathrm{~h} ; \text { mass ratio of IL/Oil, } \\
1 / 2 ; \mathrm{O} / \mathrm{S}, 60\end{array}$ & [21] \\
\hline$[\mathrm{Hnmp}]\left[\mathrm{H}_{2} \mathrm{PO}_{4}\right]$ & diesel fuel (750ppm) & $64.3 \%$ & $\begin{array}{l}\mathrm{T}, 333.15 \mathrm{~K} ; \mathrm{t}, 5 \mathrm{~h} ; \text { volume ratio of } \\
\text { IL/Oil, } 1 / 1 ; \mathrm{O} / \mathrm{S}, 16 .\end{array}$ & {$[22]$} \\
\hline [(CH2)4SO3HMIm][ZnCl3] & deisel fuel (225ppm) & $40.7 \%$ & $\begin{array}{l}\mathrm{T}, 333 \mathrm{~K} ; \mathrm{t}, 3 \mathrm{~h} \text {; mass ratio of IL/Oil, } \\
1 / 2 ; \mathrm{O} / \mathrm{S}, 30\end{array}$ & [17] \\
\hline$\left[\left(\mathrm{CH}_{2}\right)_{4} \mathrm{SO}_{3} \mathrm{HMIm}\right][\mathrm{Tos}]$ & deisel fuel (225ppm) & $43.7 \%$ & $\begin{array}{l}\mathrm{T}, 348 \mathrm{~K} ; \mathrm{t}, 3 \mathrm{~h} \text {; mass ratio of IL/Oil, } \\
1 / 2 ; \mathrm{O} / \mathrm{S}, 40\end{array}$ & {$[17]$} \\
\hline
\end{tabular}


Table 2. The component of diesel fuel

\begin{tabular}{|c|c|c|c|}
\hline Component & Mass fraction $(\%)$ & Component & Mass fraction( $\%)$ \\
\hline Undecane & 0.18 & 1-Cyclopentyl tridecane & 1.74 \\
\hline Dodecane & 0.45 & 1-Cyclopentyl tetradecane & 1.05 \\
\hline Tridecane & 1.64 & Tetradecylcyclohexane & 0.56 \\
\hline Tetradecane & 5.82 & Cetyl-cyclopentane & 0.46 \\
\hline Pentadecane & 10.87 & 3-Cyclohexylpropylcyclohexane & 1.13 \\
\hline Hexadecane & 12.6 & 4-Cyclohexyl butyl cyclohexane & 1.44 \\
\hline Heptadecane & 12.65 & 4,4'-Dimethylamino methazine & 1.19 \\
\hline Octadecane & 10.89 & Undecylbenzene & 0.97 \\
\hline Nonadecane & 9.62 & Lauryl Benzene & 0.97 \\
\hline Eicosane & 5.84 & Tridecylbenzene & 0.76 \\
\hline Twenty-one alkanes & 2.55 & 3-Ethyltetramethyl-stilbene & 1.35 \\
\hline Docosane & 0.2 & Heptamethoxime & 1.23 \\
\hline Tridecene & 0.7 & Hexane & 1.82 \\
\hline Octyl cyclopentane & 0.87 & pentane & 2.68 \\
\hline 1-cyclopentyl nonane & 0.97 & Hexahydrotoluene & 0.256 \\
\hline 1-cyclopentyl decane & 1.97 & Benzothiophene & 0.047 \\
\hline Decyl cyclohexane & 2.31 & Dibenzothiophene & 0.053 \\
\hline 1-cyclopentyl dodecane & 2.16 & Ethanethiol & 0.003 \\
\hline Dimethyl sulfide & 0.001 & & \\
\hline
\end{tabular}


Table 3. Results from simulation of desulfurization

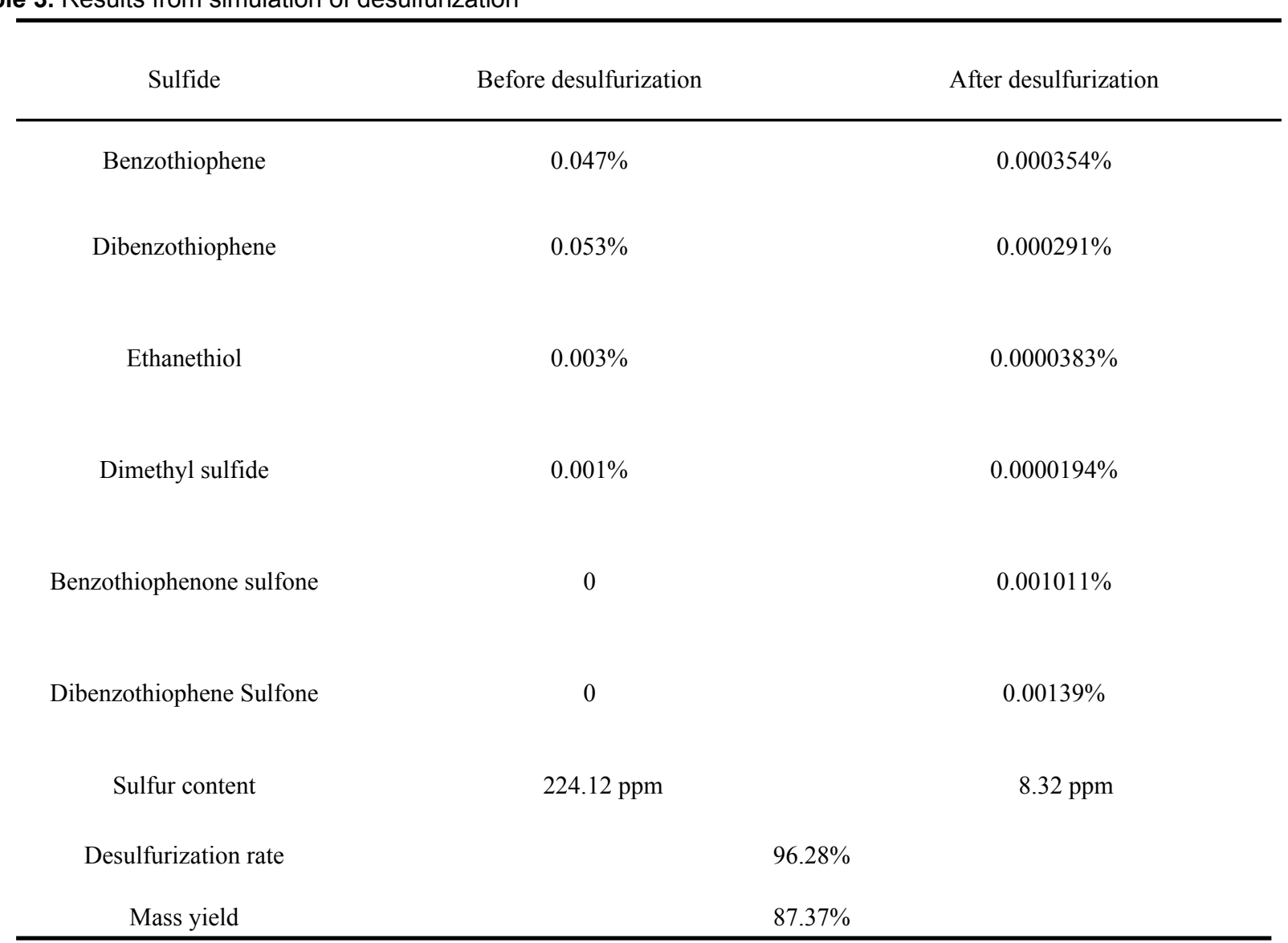


Table 4. Economical comparison of the proposed process and HDS

Environmental considerations

Energy intensive and high consumption of $\mathrm{H}_{2}$
IL ODS + solvent EDS

Oxidation and extraction units required

Low energy costs but IL makeup regeneration is

$$
\text { significant }
$$

Low impact on environment; IL recycled; consumption of $\mathrm{H}_{2} \mathrm{O}_{2}$ and solvent

Ambient operating conditions, IL toxicity not fully studied, solvent toxicity

Requires significant development 
Table 5. Experimental results of the coupled oxidation-extraction desulfurization (for $10000 \mathrm{~kg} / \mathrm{h}$ diesel fuel)

\begin{tabular}{cccccc}
\hline solvent & $\begin{array}{r}\text { temperature } \\
\left({ }^{\circ} \mathrm{C}\right)\end{array}$ & $\begin{array}{r}\text { pressure } \\
(\text { bar })\end{array}$ & $\begin{array}{r}\text { solvent-to-feed ratio } \\
(\mathrm{S} / \mathrm{F})\end{array}$ & $\begin{array}{c}\text { yield } \\
(\%)\end{array}$ & $\begin{array}{c}\text { energy consumption } \\
(\mathrm{kW})\end{array}$ \\
\hline B1 & 80 & 1 & 1 & 88.86 & 0 \\
B3 & 80 & 1 & 1 & 94.45 & 209.29 \\
B4 & 150 & 1 & $\sim$ & 96.37 & 939.15 \\
B5 & 198 & 0.8 & $\sim$ & 98.41 & 1199.39 \\
B12 & 138 & 1 & $\sim$ & 99.76 & 8985.24 \\
\hline
\end{tabular}




\section{For Table of Contents Use Only}

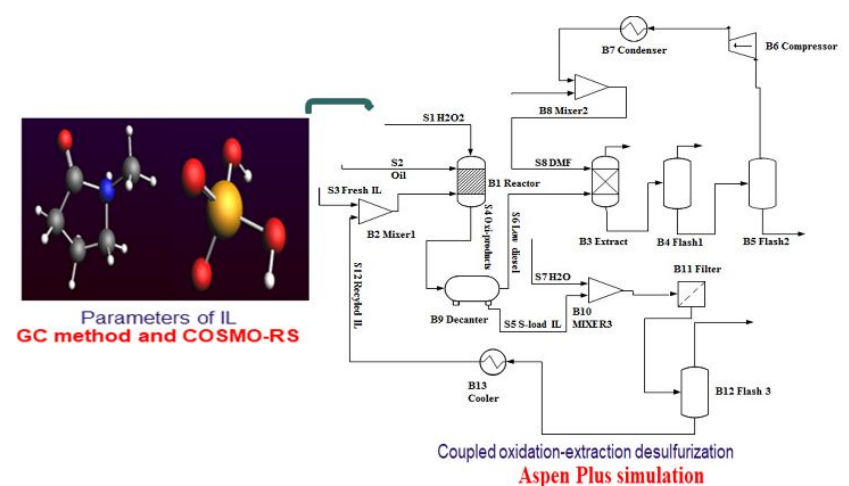

TOC Graphic: Coupled Oxidation-Extraction Desulfurization for Diesel Fuel evaluated by COSMO-RS and Aspen Plus 